\title{
The Impact Of Lecture Capture On Student Performance In Business Courses
}

\author{
Neil Terry, West Texas A\&M University, USA \\ Anne Macy, West Texas A\&M University, USA \\ Robin Clark, West Texas A\&M University, USA \\ Gary Sanders, West Texas A\&M University, USA
}

\begin{abstract}
This paper examines the effect of the e-learning technology of lecture capture on the performance of undergraduate business students in business law, economics, finance, and management courses. The sample consists of 890 student observations at a midsized regional institution located in the Southwestern region of the United States. The dependent variable is percentage score on a comprehensive final exam in advanced business courses. The empirical model controls for effort, grade point average, standardized test scores (SAT/ACT), and instruction mode. Demographic variables are gender, ethnic background, age, major, and transfer students. Effort measured via homework score, grade point average, ability measured via standardized test scores, academic major, and access to lecture capture are the five model variables that are positive and statistically significant. Age, classification as a transfer student, and online courses without lecture capture are the three statistically significant variables with a negative coefficient. The demographic variables associated with African-American, Hispanic, and gender are not statistically significant determinants of performance on the final exams. The results indicate that students completing business courses with access to lecture capture score approximately three percent higher on the final exam, holding other factors constant.
\end{abstract}

Keywords: Business Education; Emerging Educational Technology; Lecture Capture; Online Education

\section{INTRODUCTION}

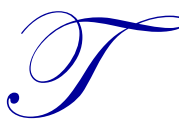

echnological changes have fundamentally altered the delivery of higher education. Electronic learning, or e-learning, is ubiquitous in higher education. Whether used as a supplement to campus courses or for completely online courses, e-learning is a basic component of almost all courses. Researchers have debated the efficacy of online instruction and corresponding techniques since its use became pervasive (Bowman, 2003; Fortune, Shifflett, \& Sibley, 2006; Terry, 2007).

Lecture capture is an asynchronous option within e-learning that combines the campus experience of the classroom with the freedom of online instruction. Lecture capture records classroom activities for later student viewing on his or her personal mobile device or computer. Lecture capture technology records the presenter's audio and video, as well as any visual aids - laptop, tablet, whiteboard, document camera, or visualizer - synchronizes them, and webcasts the stream live or archives it for on-demand playback (Sonic Foundry, 2014). However, lecture capture is not limited to just professor lectures. It can also record student presentations, student-generated videos, team activities, demonstrations, training, guest speakers, and other campus events.

This paper examines the influence of lecture capture on student performance on a comprehensive final exam in undergraduate business courses. Model variables include controls for ability, effort, grade point average, instruction mode, demographics, transfer students, and major. The research cohort for this study is a public university located in the Southwestern part of the United States. The institution is mid-sized with a total enrollment of approximately 8,500 total students with a business and economics program accredited by the Association to Advance Collegiate Schools of Business (AACSB). The organization of the manuscript includes a brief literature 
review followed by a description of the data and model. Empirical results assess the influence of lecture capture on the performance in advanced undergraduate courses in business. The final section offers conclusions and discusses the limitations of the study.

\section{LITERATURE REVIEW}

The growth in online education continues with a record 6.7 million higher education students in 2012 taking at least one online course according to the Sloan Consortium's annual report on U.S. online education. The increase in students was 9.3\% higher than in 2011 and raised the proportion of students enrolled in at least one online course to $32 \%$ (Allen \& Seaman, 2013).

While almost one-third of college students enrolled in one or more online courses, the issue of the efficacy of e-learning is not settled. Various studies, such as Bennet, Padgham, McCarty, \& Carter (2007); Brown \& Liedholm (2002); Coates, Humphreys, Kane, \& Vachris (2004); Terry (2007); and Xu \& Jaggars (2013), find significant negative differences in learning outcomes between students enrolled in traditional campus courses and online courses indicating that online courses are not as effective. However, this result is not universal. Campbell, Floyd, \& Sheridan (2002), Dirienzo \& Lilly (2014); and Neuhauser (2002) find no significant difference in learning outcomes between campus and online courses. A third cohort of research - Figlio, Rush, \&Yin (2010) and McCarty, Bennet, \& Carter (2013) - find no significant differences for a combined sample but do find significantly lower outcomes for minority groups and low achieving students. The switch to greater online education may have an asymmetric negative effect on certain student populations. Consequently, future e-learning efficacy studies should control for variant demographic characteristics.

The efficacy of e-learning intertwines with the evolution of technology. Features, tools, accessibility and usability have increased over the last two decades. Thus, the change in technology may partially explain the differences in learning outcomes as discussed above. Not only has the technology evolved, but so has the general computer literacy of students and professors. Prensky (2001) discusses the computer literacy gap in terms of "digital natives" and "digital immigrants." Digital natives are fluent in new technologies and tend to be new students and instructors. Older students and established professors are digital immigrants who struggle with effectively using newer software and hardware. Arbaugh et al. (2009) find that distinctions between student performance in campus and online courses decrease as online courses have become more widespread. If there is a technology gap, the gap is closing as both students and professors move along the learning curve. In as quickly as one semester, the performance or technological knowledge gap can close between a campus course and the corresponding online course (Kock, Verville, \& Garza, 2007).

While the research on online education is large and growing, the research on use and efficacy of lecture capture technology is in the preliminary stage of discovery. Classic lecture capture refers to a system of recording video and audio. Rich lecture capture includes computer screen capture and document camera capture (Pale, Petrović, \& Jeren, 2013). In some rich lecture capture, a picture-in-picture format is used with the majority of the screen devoted to the computer screen or document camera capture but with a small window of the speaker to help the viewer get a sense of the presentation subtleties. Lecture capture is an important step in the evolution of education delivery because it allows instructors to record and distribute lectures given on campus to online students.

Studies of lecture capture indicate a convergence of learning outcomes between campus and online classes. Newton et al. (2014) conduct a comprehensive literature review assessment of the pedagogical benefits of lecture capture and find that lecture capture as part of a face-to-face class results in increased student satisfaction, heightened content knowledge, increased control over learning, higher quality course notes, and improved academic performance. The authors find that research investigating lecture capture and class attendance are mixed, with some research indicating no influence on class attendance while other studies find lower attendance when lecture capture is used (Smyth \& Volker, 2013; Owsten, Lupshenyuk, \& Wideman, 2011). Studies such as Owsten, Lupshenyuk, \& Wideman (2011) find that grades are not worse when decreased attendance is combined with the availability of lecture capture videos. 
Research matching comparable campus and online classes with recorded lectures is limited, but encouraging, to lecture capture. Smyth \& Volker (2013) compare two sections of a macroeconomics principles course - one section a traditional lecture course and the other section an online course with lecture capture videos and find no significant differences in student performance. They did find that the withdrawal rate was twice as high for the lecture capture section. The authors used instructional delivery as the independent variable and exam and homework scores as the dependent variables but did not include any demographic variables. Euzent et al. (2011) also examine a macroeconomics principles course with two sections - one on campus and one online with lecture capture. They also find no significant differences in the final course grades between the two sections. Euzent et al. (2011) do obtain demographic information, but they exclude it from their regression testing.

There is a dearth of research on assessing the influence of lecture capture technology on student performance. This paper investigates the research gap by comparing the efficacy of campus and online courses to those that utilize lecture capture technology while controlling for various demographic and other important variables, which prior research has omitted.

\section{DATA AND MODEL}

The purpose of this section is to develop an empirical model to test student performance in undergraduate business classes that use lecture capture as supplementary support. Davisson and Bonello (1976) propose an empirical research taxonomy in which they specify the categories of inputs for the production function of learning. These categories are human capital (admission exam score, GPA, discipline major), utilization rate (study time), and technology (lectures, classroom demonstrations). Using this taxonomy, Becker (1983) demonstrates that a simple production function can be generated which may be reduced to an estimable equation. While his model is somewhat simplistic, it has the advantage of being parsimonious and testable. A number of problems may arise from this research approach (Chizmar \& Spencer, 1980; Becker, 1983). Among these are errors in measurement and multicollinearity associated with demographic data. Despite these potential problems, there must be some starting point for empirical research into the process by which there is evidence of business knowledge learning.

The choice of demographic variables to include in the model presents several difficulties. A parsimonious model is specified to avoid potential multicollinearity problems. Race and age are controversial variables to include in a learning model. Following Siegfried \& Fels (1979) and Hirschfeld, Moore, \& Brown (1995), the authors include race, gender, and age variables in the study. A number of model specifications using work experience, international student status, and concurrent hours in various combinations were considered in the preliminary stages of model specification. Inclusion of these variables into the model affected the standard errors of the coefficients but did not the value of the remaining coefficients. For this reason, they are excluded in the model. University academic records are the source of admission and demographic information because of the potential biases identified in self-reported data (Maxwell \& Lopus, 1994).

The model developed to analyze student learning for this study relies on a production view of student learning. Assume that the production function of learning business concepts via a comprehensive final exam can be represented by a production function of the form:

(1) $Y_{i}=f\left(A_{i}, E_{i}, D_{i}, X_{i}\right)$,

where $\mathrm{Y}$ measures the degree to which student $\mathrm{i}$ learns, A is information about the student's native ability, $\mathrm{E}$ is information about the student's effort, $\mathrm{D}$ is a $[0,1]$ dummy variable indicating demonstration method or mode, and $\mathrm{X}$ is a vector of demographic information. As noted above, this can reduce into an estimable equation. The specific model used in this study is:

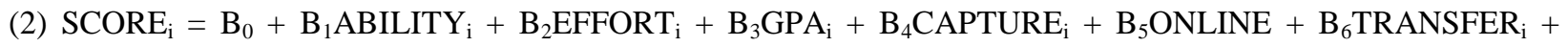
$\mathrm{B}_{7} \mathrm{AFA}_{\mathrm{i}}+\mathrm{B}_{8} \mathrm{HISPANIC}_{\mathrm{i}}+\mathrm{B}_{9} \mathrm{GENDER}_{\mathrm{i}}+\mathrm{B}_{10} \mathrm{AGE}_{\mathrm{i}}+\mathrm{B}_{11} \mathrm{MAJOR}_{\mathrm{i}}+\mathrm{u}_{\mathrm{i}}$.

The research sample consists of junior and senior students at a midsized regional institution located in the Southwestern region of the United States. The Association to Advance Collegiate Schools of Business (AACSB) 
accredits the business program studied. Table 1 presents the descriptive statistics of all variables employed in the model. The dependent variable used in the model is the percentage score on a comprehensive final exam (SCORE) in an advanced undergraduate business course. The business courses employed in the study are principles of management, strategic management, business law, corporate finance, investments, intermediate microeconomic theory, intermediate macroeconomic theory, industrial organization, and labor economics offered in the years 2013 and 2014. Junior or higher standing is required for enrollment in all of the courses. The research sample comes from 890 student enrollments in the various business courses. Because several students enrolled in more than one course, the number of unique students in the sample totals 598. The mean percentage score for the research cohort of the comprehensive final exam is $71.38 \%$ with a standard deviation of 18 . The final exam score at a mean in the $70-75 \%$ range combined with a relatively large standard deviation of both very good and relatively poor student performances yields a research cohort that is representative of a typical regional university.

Table 1: Lecture Capture Summary Statistics

\begin{tabular}{|l|c|c|c|c|}
\hline \multicolumn{1}{|c|}{ Variable } & Mean & Minimum & Maximum & Std. Deviation \\
\hline SCORE & 71.38 & 18 & 100 & 18.017 \\
\hline ABILITY & 21.59 & 13 & 33 & 3.402 \\
\hline EFFORT & 82.06 & 0 & 100 & 17.213 \\
\hline GPA & 2.79 & 0.88 & 4.0 & 0.511 \\
\hline CAPTURE & 0.21 & 0 & 1 & 0.204 \\
\hline ONLINE & 0.38 & 0 & 1 & 0.337 \\
\hline TRANSFER & 0.51 & 0 & 1 & 0.446 \\
\hline AFA & 0.03 & 0 & 1 & 0.168 \\
\hline HISPANIC & 0.22 & 0 & 1 & 0.422 \\
\hline GENDER & 0.41 & 0 & 61 & 0.492 \\
\hline AGE & 25.21 & 19 & 1 & 6.001 \\
\hline MAJOR & 0.33 & 0 & & 0.417 \\
\hline
\end{tabular}

Note: $\mathrm{n}=890$.

The ACT entrance exam or SAT converted to ACT equivalency measures student academic ability (ABILITY). The average ACT score for the research cohort is 21.59 (equivalent to 1020 on the math/reading SAT or 1550 on the 2400-point SAT). The ABILITY variable via the ACT exam is a proxy for innate student ability before entering the university. Student ability as measured by the ACT exam is expected to have a positive impact on final exam score.

The model measures effort via homework score. The business courses in the research cohort all require homework assignments. The homework score is a proxy for effort given the assignments are open for completion across several weeks and students have multiple opportunities to ask course instructors questions should there be a need for clarification. In addition, students can employ textbook, web, and other resources to help complete homework assignments. The average value for the EFFORT variable is $82 \%$ with a standard deviation of $17 \%$. Student effort via homework is expected to have a positive impact on the final exam score.

Grade point average (GPA) is included in the model based on research indicating that grade point average is one of the primary positive determinants of student performance on comprehensive exams (Black \& Duhon, 2003; Terry, Walker \& Kelly, 2010). Student grade point average in the study for the cohort is 2.79 with a standard deviation of approximately half a grade point, at 0.511 . GPA is expected to have a positive impact on the final exam score in undergraduate economics courses.

The categorical variable CAPTURE represents student enrollment in a course employing lecture capture technology. Lecture capture is an umbrella term describing any technology that allows instructors to record what happens in their classrooms and make it available digitally (Educause, 2008). In its simplest form, lecture capture can be an audio recording made with an iPod; alternatively, the term may refer to a software capture program that records cursor movement, typing, or other on-screen activity. Lecture capture systems offer three important benefits: 1) an alternative when students miss class; 2) an opportunity for content review; and 3) content for online course development (Educause, 2008). Lecture capture enhances and extends existing instructional activities, whether in face-to-face, fully online, or in blended learning environments. In this study, the lecture capture tool includes the 
ability to record an entire course lecture and post the audio and video recordings online to support students that miss class and to provide an opportunity to review lecture content multiple times outside of the classroom for students taking either a campus or online course. Approximately twenty-one percent of the students in the research cohort completed business courses supported by the lecture capture tool. The CAPTURE variable is expected to have a positive impact on final exam score. Augmenting the online education environment with lecture capture is of particular interest because current students may gravitate toward the convenience of asynchronous learning. Despite the convenience, many researchers question the quality control and efficacy of the online environment (Bowman, 2003; Fann \& Lewis, 2001; Fortune, Shifflett \& Sibley, 2006). In contrast to the CAPTURE variable, the variable ONLINE is part of the model to control for students taking online classes without supporting lecture capture content. The expectation is that traditional online courses that do not include lecture capture will have a negative impact on student performance. Thirty-eight percent of the student enrollments in the research cohort are from online courses.

The variable TRANSFER is included in the model as a demographic variable controlling for students that complete six or more courses (e.g., 18 credit hours) at an alternative institution, which is usually a two-year community college. Transfer students represent fifty-one percent of the students in the research cohort. The transfer variable is expected to have a negative impact on final exam scores in business classes based on the assumption that foundational core classes at a community college are not expected to meet the rigor of similar courses at a four-year university.

Four demographic variables are included in the model. The demographic variables AFA and HISPANIC are included in the study to test for possible differences in final exam performance across ethnic groups. African American students (AFA) represent three percent of the research cohort and Hispanic students are at twenty-two percent. The variable GENDER is included in the model based on the finding of researchers (Bagamery, Lasik \& Nixon, 2005; Black and Duhon, 2003; Mirchandani, Lynch \& Hamilton, 2001) that male student performance on standardized exams is higher than female. Females represent forty-one percent of the research cohort. The last demographic variable in the model is AGE. Average age for the research cohort is 25 with a standard deviation of 6.

The final variable in the model is a control variable for major. The variable controls for student performance in courses directly related to a specific major (i.e., controls for finance majors enrolling in a finance course, management majors enrolling in a management course, economics majors enrolling in an economics course, etc...). Thirty-three percent of the students in the research cohort represent enrollment within the same discipline as the student major. The expectation is for the MAJOR variable to have a positive impact on SCORE. Business programs tend to focus on critical thinking skills in ways that are prescriptive with respect to curriculum and performance expectations. Students taking courses in the discipline that represents the major are likely to perform at a higher level on a comprehensive final exam within the discipline.

\section{RESULTS}

Results from the ordinary least squares estimation of Equation (2) are presented in this section and Table 2. The sample cohort is derived from students in nine different business courses taking a comprehensive course final exam in 2013 and 2014. The total usable sample size is 890 observations, with 98 student observations eliminated from the global sample because of incomplete information, usually relating to the lack of ACT/SAT scores (Douglas \& Joseph, 1995). None of the independent variables in the model have a correlation higher than 0.50 , providing evidence that the model specification does not suffer from excessive multicollinearity. The Equation (2) model explains over 60 percent of the variance in performance on comprehensive final exam scores in undergraduate business courses at a regional business school. Eight of the eleven independent variables in the model are statistically significant. 
Table 2: Estimation Of Equation (2)

\begin{tabular}{|l|c|c|}
\hline \multicolumn{1}{|c|}{ Variable } & Coefficient & t-statistic \\
\hline Intercept & 8.167 & 5.62 \\
\hline ABILITY & 1.332 & $8.03^{*}$ \\
\hline EFFORT & 0.441 & $3.94^{*}$ \\
\hline GPA & 6.042 & $2.37^{*}$ \\
\hline CAPTURE & 3.282 & $-2.20^{*}$ \\
\hline ONLINE & -2.895 & $-2.78^{*}$ \\
\hline TRANSFER & -4.112 & 0.38 \\
\hline AFA & 1.667 & -0.69 \\
\hline HISPANIC & -1.304 & 0.88 \\
\hline GENDER & 1.214 & $-2.16^{*}$ \\
\hline AGE & -0.267 & $3.34^{*}$ \\
\hline MAJOR & 6.313 & \\
\hline
\end{tabular}

Notes: R-square $=.6038, \mathrm{~F}=36.28,{ }^{*} \mathrm{p}<.05$, and $\mathrm{n}=890$.

Three of the variables with a positive coefficient and statistical significance are ABILITY, GPA, and EFFORT. The empirical results imply that student scores on final exams in business are directly related to academic ability measured by the ACT college entrance exam, academic performance measured by college grade point average, and effort measured by homework grade as a proxy. The statistically significant impact of standardized entrance exam scores and grade point average is consistent with previous research (Mirchandani, Lynch \& Hamilton, 2001). The significance of the ABILITY variable provides support for the notion that students with innate academic ability perform at a relatively high level on all forms of examinations. The results relating to the ACT exam are somewhat tempered by the observation that approximately ten percent of the students in the initial sample were eliminated primarily for not having an official ACT/SAT score posted with the university. The positive and significant impact of GPA on the final exam is not surprising. It is reasonable to assume that students with high grades normally perform at a higher academic level on various performance metrics than students with a relatively low grade point average. Consistent with Mirchandani et al. (2001), overall GPA has a strong internal validity and provides a measure of student performance related to the curriculum of the school. The highest t-value in the model is associated with the EFFORT variable. The relatively large standard deviation of 17.2 associated with the variable implies that effort put forth was not consistent across the research cohort.

One of the more intriguing results from the study revolves around the variable CAPTURE. Holding constant ability, effort, grades, major, transfer student status, online-only courses, and demographic considerations, students completing business courses with lecture capture support scored approximately three percent higher on the comprehensive exam. The result is statistically significant (t-stat of 2.37). The significant statistical result implies that supplementing course instruction with online lecture capture materials produces a learning environment that is statistically superior to the traditional campus environment. The ability to review lecture materials multiple times before an exam or for a missed class appears to augment student performance on the final exam for undergraduate business courses. In contrast, the online mode without any lecture capture support produces final exam scores that are approximately three percent lower than traditional campus courses. The combined results imply that lecture capture is likely to be an important tool in the long-run viability of online instruction as both a tool to enhance traditional campus courses or to offer more explicit content in stand-alone online courses.

The empirical results yield a negative coefficient and statistical significance for the TRANSFER variable. The results imply that students transferring eighteen or more hours from another institution score approximately four percent lower on a comprehensive exam in an undergraduate business course, controlling for factors like effort, ability, major, instruction mode, and demographic characteristics. This result is somewhat surprising given previous results in the literature (Terry, Walker \& Kelley, 2010). The general stereotype that students starting at a community college receive a less rigorous foundation education appears verified in this study. Although it is possible that foundational core classes at a community college do not meet the rigor of similar courses at a four-year university, it is also possible that the four-year university admits students as freshman with stronger academic skills. Additionally, students admitted to the four-year institution as a freshman completed principles of economics, principles of accounting, principles of business statistics, and other foundation courses at the institution. As a result, the students 
may have an advantage of already knowing information about the approach, style, and focus of the faculty members participating in the research cohort.

The model results include four demographic variables. Only one of the demographic variables in the model is statistically significant. The AGE variable is negative and statistically significant. The result implies that older students are more likely to struggle on the final exam in business courses. It is possible that the quantitative aspect of the economics and finance courses in the research sample is a challenge for older students as they are further removed from their foundation training in math and statistics? The variables AFA, HISPANIC, and GENDER do not produce a t-statistic that is greater than 1.0. The statistical insignificance is interesting but not surprising. Controlling for variables such as ability, effort, and GPA, there is no ethnic or gender differential with respect to performance on the final exam for the research cohort.

The last variable in the model is a categorical variable comparing the performance of students taking courses in the major discipline versus students taking courses in order to complete the program business core. The empirical results indicate the MAJOR variable is positive and statistically significant. The results imply majors score approximately six percent higher on the final compared to peers from other majors. Students in all majors complete multiple classes within the discipline and should have an advantage of discipline-specific training depth combined with strong content interest stemming from self-selection into the major. Economics, finance, and management are the relevant majors for this research.

\section{CONCLUSION}

This study examines the determinants of student performance on comprehensive exams in undergraduate business courses offered to junior and seniors with a focus on the impact of lecture capture. The results indicate that eight of the eleven model variables have a statistically significant impact on exam performance. The variables controlling for effort, ability, grade point average, lecture capture and major are positive and statistically significant, while designation as a transfer student, completing work online without lecture capture, and age have negative coefficients that are statistically significant. Some of the more interesting observations about performance on the final exam are that transfer students score four percent lower, online students with no lecture capture support score approximately three percent lower, and access to lecture capture increases final exam score by three percent. Ethnic background and gender do not have a statistically significant impact on exam performance.

The positive impact of lecture capture is encouraging as an e-learning tool that augments course content by providing students access to materials when missing class plus offers an opportunity to review materials multiple times outside of the classroom. Lecture capture technology is still in the infancy stage of the e-learning movement, but the prospect of expanding access to traditional face-to-face lectures is critical given the trend of increasing online-delivered content.

One significant limitation of the research is that one academic institution is the source of all data. It is hard to know if the institution hosting the research cohort is unique or generally representative of regional institutions. In addition, the lecture capture technology employed at one institution might be slightly different compared to other institutions. A more robust sample of multiple institutions should be a focus of future research to verify the consistency of the empirical results. A second focus for future research is to move beyond a few business courses in application. A true measure of the viability of lecture capture in a business school should employ multiple courses from, marketing, accounting, management information systems, and other business disciplines. The results of this study provide evidence that lecture capture is an effective tool in a limited number of economics, finance, business law, and management classes, but it is unknown if the tool will be more or less effective when offered to a more robust collection of business courses.

\section{AUTHOR INFORMATION}

Dr. Neil Terry is dean and professor of economics at West Texas A\&M University in Canyon, Texas. Dr. Terry earned a doctorate degree in economics from Texas Tech University. E-mail: nterry@wtamu.edu. 
Dr. Anne Macy is the Gene Edwards Professor of Finance at West Texas A\&M University in Canyon, Texas. Dr. Macy earned a doctorate degree in economics and finance from Texas Tech University. E-mail: amacy@wtamu.edu.

Dr. Robin Clark is clinical assistant professor of Business Law at West Texas A\&M University in Canyon, Texas. Dr. Clark earned her J.D. from the University of Texas and has worked in the private sector as a lawyer for over 20 years before taking a faculty position. E-mail: rclark@wtamu.edu.

Dr. Gary Sanders is clinical assistant professor of business law and accounting at West Texas A\&M University in Canyon, Texas. Dr. Sanders earned his J.D. from Texas Tech University and has worked in the private sector as a lawyer for over 30 years before taking a faculty position. E-mail: gsanders@wtamu.edu.

\section{REFERENCES}

1. Allen, I. E., \& Seaman, J. (2013). Changing course: Ten years of tracking online education in the United States. Sloan Consortium. PO Box 1238, Newburyport, MA 01950.

2. Arbaugh, J. B., Godfrey, M. R., Johnson, M., Pollack, B. L., Niendorf, B., \& Wresch, W. (2009). Research in online and blended learning in the business disciplines: Key findings and possible future directions. The Internet and Higher Education, 12(2), 71-87.

3. Bagamery, B., Lasik, J., \& Nixon, D. (2005). Determinants of success on the ETS Business Major Field Exam for students in an undergraduate multisite regional university business program. Journal of Education for Business, 81(1), 55-63.

4. Becker, W. (1983). Economic education research: New directions on theoretical model building. Journal of Economic Education, 14(2), 4-9.

5. $\quad$ Bennett, D. S., Padgham, G. L., McCarty, C. S., \& Carter, M. S. (2007). Teaching principles of economics: internet vs. traditional classroom instruction. Journal of Economics \& Economic Education Research, 8(1), 21-31.

6. Black, H., \& Duhon, D. (2003). Evaluating and improving student achievement in business programs: The effective use of standardized tests. Journal of Education for Business, 79(2), 90-98.

7. Bowman, J. P. (2003). It's not easy being green: Evaluating student performance in online business communication courses. Business Communication Quarterly, 66(1), 73-78.

8. Brown, B. W., \& Liedholm, C. E. (2002). Can web courses replace the classroom in principles of microeconomics? American Economic Review, 92(2), 444-448.

9. Campbell, M. C., Floyd, J., \& Sheridan, J. B. (2002). Assessment of student performance and attitudes for courses taught online versus onsite. Journal of Applied Business Research, 18(2), 45-51.

10. Chizmar, J., \& Spencer, D. (1980). Testing the specifications of economics learning equations. Journal of Economic Education, 11(2), 45-49.

11. Coates, D., Humphreys, B. R., Kane, J., \& Vachris, M. A. (2004). No significant distance between face-toface and online instruction: evidence from principles of economics. Economics of Education Review, 23(5), 533-546.

12. Davisson, W., \& Bonello, F. (1976). Computer assisted instruction in economics education. University of Notre Dame Press.

13. DiRienzo, C., \& Lilly, G. (2014). Online versus face-to-face: Does delivery method matter for undergraduate business school learning? Business Education \& Accreditation, 6(1), 1-12.

14. Douglas, S., \& Joseph, S. (1995). Estimating educational production functions with correction for drops. Journal of Economic Education, 26(2), 101-112.

15. Educause. (2008). Seven things you should know about lecture capture. Retrieved May 24, 2014 from http://www.educause.edu/library/resources/7-things-you-should-know-about-lecture-capture.

16. Euzent, P., Martin, T., Moskal, P., \& Moskal, P. (2011). Assessing student performance and perceptions in lecture capture vs. face-to-face course delivery. Journal of Information Technology Education: Research, 10(1), 295-307.

17. Fann, N., \& Lewis, S. (2001). Is online education the solution? Business Education Forum, 55(4), 46-48.

18. Figlio, D. N., Rush, M., \& Yin, L. (2010). Is it live or is it internet? Experimental estimates of the effects of online instruction on student learning (No. w16089). National Bureau of Economic Research. 
19. Fortune, M. F., Shifflett, B., \& Sibley, R. (2006). A comparison of online (high tech) and traditional (high touch) learning in business communication courses in Silicon Valley. Journal of Education for Business, 81(4), 210-214.

20. Hirschfeld, M., Moore R., \& Brown, E. (1995). Exploring the gender gap on the GRE subject test in economics. Journal of Economic Education, 26(1), 3-15.

21. Kock, N., Verville, J., \& Garza, V. (2007). Media naturalness and online learning: Findings supporting both the significant-and no-significant-difference perspectives. Decision Sciences Journal of Innovative Education, 5(2), 333-355.

22. Mawell, N., \& Lopus, J. (1994). The Lake Wobegon effect in student self-reported data. American Economic Review, 84(2), 201-205.

23. McCarty, C., Bennett, D., \& Carter, S. (2013). Teaching college microeconomics: Online vs. traditional classroom instruction. Journal of Instructional Pedagogies, 11(1), 20-28.

24. Mirchandani, D., Lynch, R., \& Hamilton, D. (2001). Using the ETS Major Field Test in business: Implications for assessment. Journal of Education for Business, 77(1), 51-56.

25. Neuhauser, C. (2002). Learning style and effectiveness of online and face-to-face instruction. American Journal of Distance Education, 16(2), 99-113.

26. Newton, G., Tucker, T., Dawson, J., \& Currie, E. (2014). Use of lecture capture in higher education: Lessons from the trenches. TechTrends, 58(2), 32-45.

27. Owston, R., Lupshenyuk, D., \& Wideman, H. (2011). Lecture capture in large undergraduate classes: Student perceptions and academic performance. The Internet and Higher $\quad$ Education, 14(4), 262268.

28. Pale, P., Petrović, J., \& Jeren, B. (2013). Assessing the learning potential and students' perception of rich lecture captures. Journal of Computer Assisted Learning, 30(2), 187-195.

29. Prensky, M. (2001). Digital natives, digital immigrants part 1. On the horizon, 9(5), 1-6.

30. Siegfried, J., \& Fels, R. (1979). Research on teaching college economics: A survey. Journal of Economic Literature, 17(3), 923-969.

31. Smyth, E. G., \& Volker, J. X. (Eds.). (2013). Enhancing instruction with visual media: Utilizing video and lecture capture. IGI Global.

32. Sonic Foundry. (2014). Lecture capture definitions and approaches. Retrieved May 24,2014 from http://www.sonicfoundry.com/webcasting-solutions/what-is-lecture-capture.

33. Terry, N. (2007). Assessing instruction modes for master of business administration (MBA) courses. Journal of Education for Business, 82(4), 220-225.

34. Terry, N., Walker, J., \& Kelley, G. (2010). The Determinants of Student Performance on the Business Major Field ETS Exam: Do Community College Transfer Students Make the Grade? The Journal of Human Resource and Adult Learning, 6(1), 1-8.

35. Xu, D., \& Jaggars, S. S. (2013). The impact of online learning on students' course outcomes: Evidence from a large community and technical college system. Economics of Education Review, 37(1), 46-57. 
NOTES 